\section{RECURSOS NATURAIS E TURISMO Tendências Contemporâneas}

Olga Tulik

RESUMO: Este artigo aborda a questão dos recursos naturais e seu aproveitamento para a recreação e o turismo. As tendências contemporâneas no Brasil se inclinam para a utilização de recursos naturais básicos, associados a equipamentos e serviços adicionais, implicando na renovaçāo de modalidades de uso do tempo livre e criando formas de ocupação do espaço.

PALAVRAS-CHAVE: Turismo; recursos naturais; tendências; oferta.

ABSTRACT: This article is about the question of natural resources and its utilization for tourism and recreation. InBrazil, the contemporarytendencies turns to the use of basic natural resources, associated to added equipments and services. It leads toa renovation of different uses of free times and creates new kinds of space occupancy.

KEYWORDS: Tourism; natural resources; tendencies; supply.

\section{INTRODUÇÃO}

A preocupação com o uso e, também, com a conservação de recursos naturais no Brasil vêm sendo objeto de discussão, no âmbito da Geografia, desde a década de 60 (GUERRA, 1969:13). Atualmente, o pensamento ecológico, através de suas vertentes (conservacionismo, ecologismo e ambientalismo) tradicionais ou radicais alcança governantes, empresários, acadêmicos e o público em geral e, entre estes, aqueles que se dedicam ao turismo.

1 Doutora em Ciências Humanas. Professora Assistente Doutora do Curso de Turismo do Departamento de Relações Públicas, Propaganda e Turismo da ECA-USP.

End. para corresp.: Escola de Comunicações e Artes da USP - Departamento de Relações Públicas, Propaganda e Turismo - Cidade Universitária "Armando de Salles Oliveira" - Av. Prof. Lúcio Martins Rodrigues, 443, bloco B - CEP 05508-900 - São Paulo - SP - Brasil.
Assim, abordar questões relacionadas ao aproveitamento de recursos naturais pelo turismo é, no mínimo, oportuno considerando-se as tendências naturamporâneas da promoção e ocupação turística de certas localidades.

O significado dos recursos naturais pode ser melhor avaliado pela sua importância no inventário e na classificação da oferta que, por sua vez, constituem a base de qualquer projeto dirigido para o planejamento turístico. Na maioria das vezes, entretanto, esta etapa é eliminada, seja pela ocupação espontânea, alheia aos critérios e necessidades do planejamento, seja pela pressa dos agentes e promotores turísticos em auferir lucros imediatos. Neste caso, esse comportamento reflete atitudes, naturalmente compreensiveis, como a intenção de lucro dos agentes encarregados da promoção turística e a decisão política de governantes ansiosos em experimentar, rapidamente, os efeitos da rentabilidade dos recursos sob seu controle

Na prática, é de certo modo comum, tanto na procura espontânea como na indução do fluxo que, a análise e a própria utilização dos recursos naturais sejam subestimados. Percebe-se a gravidade deste fato quando se observa que os recursos naturais constituem, pelo menos num primeiro momento, a razão maior dos deslocamentos turísticos com objetivos de recreação e de lazer.

A importância da avaliação dos recursos turísticos em geral e, em particular, daqueles derivados da natureza, pode ser verificada pelo emprego de uma grande variedade de métodos e técnicas que vêm sendo aplicados ao turismo, como aquelas apresentadas por PEARCE (1988) e SMITH (1992), entre outros. Entretanto, discutir sobre a melhor adequação dos diferentes métodos e técnicas não é o objetivo deste artigo que procura, apenas, considerar aspectos dos recursos naturais enquanto atrativos turísticos e revelar tendências contemporâneas de seu aproveitamento no Brasil.

\section{RECURSOS NATURAIS E ATRATIVOS TURÍSTICOS}

Os recursos naturais básicos constituem elementos primários da oferta e, embora presentes em todos lugares, só podem ser considerados como turísticos quando explorados para tal fim. Antes disso, integram a oferta potencial. Desta forma, concorda-se com CAZES, LANQUAR \& RAYNOUARD (1980:35) quando afirmam que não existem recursos turísticos "por si só", mas somente recursos "explotáveis" e utilizáveis que, para chegarem a ser oferta turística, precisam de condições econômicas c tecnológicas particularizadas. GUNN (1988: 37) vai mais longe ao afirmar que as atrações estão baseadas, em primeiro lugar, nos recursos naturais e que, hoje, elas são produzidas e não existem, verdadeiramente, até serem providas de facilidades. Este é o primeiro passo para melhor compreender a 
transformação de recursos naturais (o que se aplica também aos culturais) em turísticos.

Os recursos naturais correspondem às especificidades de determinadas áreas (condições gcoecológicas, por exemplo) e se constituem no fundamento para identificação de sítios $\mathrm{c}$ regiões potencialmente favoráveis ao desenvolvimento turístico. A distribuição destes recursos tem servido como instrumento de explicação geográfica para compreender padrõcs de ocupação e de transformação de áreas turísticas.

Embora a localização de recursos naturais capazes de se constituírem $\mathrm{cm}$ atrativos possa ser acidental, a sua exploração, e conseqüente transformação em recursos turísticos, é sempre intencional. Em São Paulo, por exemplo, a descoberta de algumas fontes minerais, que resultaram da procura pelo petróleo, deram origem a importantes centros receptivos com o aproveitamento de sua vocação tcrmal.

Em princípio, qualquer componente da natureza pode ser considerado na avaliação da potencialidade turística. A exploração, entretanto, não é determinada apenas pela qualidade dos recursos $\mathrm{cm}$ si, mas também por uma série de condições favoráveis como a proximidade de centros emissores, o que torna positiva a rclação tempo-custo-distância entre o emissor e o receptor facilitando o deslocamento. Além disso, a presença e a qualidade dos meios de transporte, bem como os avançostecnológicos dos meios de locomoção são fatores decisivos para o sucesso e o desenvolvimento turístico apoiado em recursos naturais.

Em geral a cxploração de recursos naturais para o turismo ocorre com onde partem fluxos consideráveis e, também, de centros urbanos de expressão regional, que garantem uma demanda menos volumosa, mas que não pode ser menosprezada. Trata-se, neste caso, do turismo de fim de semana e do chamado lazer de proximidade estudados por vários especialistas, que temas (FORNEAU, 1983:120, 619-24).

Nem todos os recursos naturais têm o mesmo grau de atratividade, pois cste vai depender, numa primeira instância, do encontro entre o recurso e a divulgação. Todavia, o grau de atratividade de um recurso turístico natural nem sempre está em correlação com a magnitude intrínseca que ele detém, mas vai depender da capacidade de scus promotores em transformá-lo numa atração. Ilustram este caso a Chapada Diamantina (Bahia) e Vila Velha

(Paraná) que têm poder de atração próprio, mas que só se firmaram como atrativos após a sua promoção e divulgação. Isto significa que é preciso investir num recurso para que estc se transforme numa atração. Neste maior intensidade nas vizinhanças de áreas intensamente urbanizadas, de desenvolvcram tcorias acerca de fenômenos cspecíficos relacionados a estes percepção do turista e, também, dos interessados pela sua promoção $c$

particular, analisando o poder de atração de um recurso turístico, GUNN (1988:40) observa que, para promovê-lo, os únicos limites são a imaginação e criatividade. A simples leitura de jornais e revistas oferece uma multiplicidade de exemplos que, em alguns casos, registram verdadeiros "vôos livres" desses processos psicológicos envolvendo a exploração de recursos turísticos ${ }^{2}$.

Muitas vezes se estabelecem relações de identidade entre os núcleos emissor e receptor que fortalecem a atratividadc, ou seja, as pessoas procuram certas áreas porque se identificam com elas; o inverso também pode ocorrer, pois certas pessoas se sentem atraídas pelo contraste de algumas áreas em relação ao seu cotidiano. É a atração pelo inusitado (PENTEADO, 1992:17).

A força turística de um recurso natural é sempre relativa, c vai depender de particularidades individuais e culturais e, também, do contexto físico que abriga este recurso, das condições de acesso, da disponibilidade de tempo livre das pessoas, dos equipamentos e serviços adicionais oferecidos.

Vários fatores podem contribuir para a valorização de um recurso turístico natural que, assim, se transforma numa atração. Isto pode ocorrer por exemplo, pela valorização social ou pela justaposição de recursos adicionais (da oferta técnica ou cultural), como foi o caso de Caldas Novas (Goiás) que tem, na Pousada do Rio Quente, a presença de fontes termais associadas a uma complexa oferta de equipamentos e serviços.

No que se refere ao turismo de fim de semana, a relação tempo-custodistância pode contribuir para a valorização de recursos turísticos naturais mais próximos dos centros emissores que são preferidos a outros, de qualidade superior, porém mais distantes. Este fato serve para explicar a eleição de áreas dotadas de recursos naturais que estão localizadas nas proximidades de centros urbanos. Juquitiba, situada a 70 quilômetros da capital paulista, vem se firmando como uma área muito procurada nos fins de semana e feriados prolongados, graças a uma série de fatores favoráveis a reduzida distância que a separa de um pólo emissor importante, as boas condições de acesso, o baixo custo de permanência em virtude de apresentar uma oferta relativamente ampla de campings e, além disso, em ambiente agradável e englobando diversas categorias de conforto; e, finalmente, a sua definição como reduto de segundas-residências favorecida pelos empreendimentos imobiliários.

O poder de atração de um recurso turístico natural valorizado pode manter uma certa constância, muito embora a sua utilização e função possam

2 O SPA Camalback

perto de Scottsdale (Estados Unidos), oferece aos seus hóspedes uma mulheres. Embade - o "aeroboxing" (mistura de ginástica aeróbica e boxe), para homens e modalidades mostra aquestãodolin 
ser alteradas no decorrer do tempo. Foz do Iguaçu (Paraná) ilustra este exemplo, pois conseguiu captar um fluxo constante, mantendo assim a sua atratividade, embora apoiada em outros elementos decorrentes de novas formas de uso do solo, de prestação de serviços e de sua posição de fronteira

Convém lembrar que os atrativos (naturais ou não), juntamente com os equipamentos e serviços auxiliares e a infra-estrutura integram a oferta devem ser compreendidos e analisados através das inter-relações que se estabelecem neste conjunto.

\section{TENDÊNCIAS CONTEMPORÂNEAS}

Alguns aspectos merecem ser considerados quando se observam as tendências contemporâneas no Brasil, a propósito do aproveitamento turístico de recursos naturais. Entretanto, outras tendências do mercado não podem ser menosprezadas pois, do ponto de vista geográfico, contribuem para explicar, não apenas a atratividade de certos recursos naturais e variações no seu aproveitamento como, também, a sua valorização. É o caso da segmentação da demanda (LAGE, 1992) cada vez mais presente na oferta de pacotes turísticos; da busca pela excelência de qualidade nos equipamentos e serviços e das tentativas feitas para alcançar o mercado internacional concretizadas, por exemplo, pela presença de um fluxo do Cone Sul que já se estende a várias regiões brasileiras e pelo interesse de norte-americanos no Nordeste do Brasil.

No tocante ao tema deste artigo, as tendências contemporâneas observadas no Brasil parecem, num primeiro momento, convergir para a mentalidade ambientalista (assumida por modismo ou conviç̧ão) que pode explicar o crescimento de certas modalidades turísticas e de atividades de recreação fundamentadas em recursos naturais básicos. É o caso da permanência na procura pelo sol, areia e mar que se fortalece com o incremento do turismo náutico que, por sua vez, engloba as represas; do turismo ecológico e de aventura que vêm estimulando a procura de áreas singulares ou exóticas; do recrudescimento do termalismo; da proliferação de SPAs e clubes de saúde; além de tendências menos expressivas, mas que já vêm alcançando uma demanda cada vez mais compartimentada, como é o caso dos roteiros esotéricos apoiados em recursos naturais básicos (propriedades terapêuticas e energéticas de certas rochas, qualidade do ar etc.).

No Brasil, apesar das campanhas contra os males provocados pelo sol, o turismo e a recreação apoiados neste componente, na areia e no mar ainda permanecem significativos e tendem a crescer muito mais com o despontar do turismo náutico: no litoral e no interior, a oferta turística fundamentada em recursos naturais básicos se multiplica, cada vez mais, procurando atender a todos os gostos, idades e estilos de vida. As superfícies líquidas ganham status de atração, principalmente quando são complementadas por equipamentos e serviços adicionais oferecidos nas áreas adjacentes ou, mesmo, nas vizinhanças.

O turismo litorânco, ponto de partida para muitos turistas que buscam osol, embora pouco estudado no Brasil, já começoua interessar os governantes que se preocupam em planejar e disciplinar esta modalidade, adotando algumas medidas, como o controle do fluxo (terminais turísticos) e as campanhas de conscientização para evitar a poluição das praias. Todavia, merecem menção as tentativas feitas por governantes e cmpresários para alcançar o receptivo internacional. O Projeto Linha Verde, por exemplo, reúne administradores, prefeitos e secretários de turismo do litoral de São Paulo e Rio de janeiro, que vêm atuando nesse sentido, inclusive mantendo escritórios em Buenos Aires (Argentina) objetivando promover, no Cone Sul, a orla litorânea entre Parati (Rio de Janeiro) e Santos (São Paulo). Alguns trechos litorâneos do Nordeste Brasileiro, como do Ceará, Pernambuco e Rio Grande do Norte entre outros, tamuém vêm despertando o interesse crescente de turistas e investidores estrangeiros, notadamente de norte-americanos.

Uma tendência contemporânea observada no Brasil é o despertar do turismo náutico, que engloba a navegação recreativa, até agora reservado a uma minoria, muito embora compreenda práticas individuais e coletivas que poderiam ser dirigidas a demandas de diferentes níveis socioeconômicos.

$\mathrm{O}$ que se verifica, entretanto, é o interesse pelo turismo náutico envolvendo modalidades de alto custo, como os cruzeiros marítimos ${ }^{3}$ na costa brasileira e a propriedade de embarcações, principamente de tamanho médio (22 pés).

Os cruzeiros maritimos na costa brasileira, iniciados na década de 50. que conheceram seu apogcu na década de $60 \mathrm{com}$ a instituição do réveillon a bordo do navio, voltaram a aparecer nos pacotes de fim de ano e, mais recentemente, nos de carnaval. Todavia, poucas empresas exploram esta modalidade e, além disso, os portos nem sempre têm a importância que deveriam ter para se constituírem em núcleos receptivos capazes de atender a uma demanda exigente, muito embora deva ser considerado que, hoje, alguns navios são verdadeiros hotéis flutuantes, organizados para oferecer, aos passageiros, os mais diversos serviços.

Todavia, algumas variações de uso coletivo poderiam atender demandas de níveis socioeconômicos diferenciados. Esta possibilidade já ocorreu 3 Em janeiro de 1994 , os pacotes para o carnaval, para um periodo de 10 dias, estavam sendo
comercia lizados ao custo de US $\$ 1600$ por pessoa (O ESTADO DE S. PAULO, 20 jan. 1994,
folha folha A2). 
e continua acontecendo no aproveitamento de roteiros fluviais (rios São Francisco e Itajai, por exemplo) com eclusas (Barra Bonita), mas a oferta é insignificante, considerando-se o grande potencial brasileiro. Da mesma forma, ainda não foi convenientemente explorada no Brasil a navegação de cabotagem, com paradas em pequenos portos da rota comercial que poderia oferecer roteiros a baixo custo destinados a um turismo popular.

O turismo náutico (VIZCARRA, 1990) que envolve a propriedade de embarcações exige, por isso mesmo, custos elevados para a construção de instalações náuticas, como marinas e portos de recreio, e serviços como postos de mecânica e de abastecimento, alojamentos, reparo de embarcações (tapeçaria, pintura), restaurantes, lojas de produtos náuticos, estacionamento, vestiários etc. Além disso, envolve o poder público, uma vez que necessita de regulamentação e espaços especificos. Atualmente, os esforços estão dirigidos para a construção de marinas, pois a falta de local adequado para guardar as embarcações vem sendo apontada como responsável pela retração das vendas

Apesar desta evolução marcada pela colocação no mercado de mais de 4 mil embarcações de recreio por ano e pela presença de cerca de 40 estaleiros destinados ao reparo de embarcações de lazer, a navegação recreativa no Brasil ainda não é tão expressiva que possa ocasionar transtornos de circulação marítima, como acontece em outros países. Isto se explica pelo atraso no desenvolvimento do turismo náutico, nãoapenas em virtude do alto custo dos equipamentos específicos, serviços e infra-estrutura necessários para a prática e implantação desta modalidade, mas também pela falta de tradição marítima no Brasil.

Resta acrescentar que vem ganhando força a prática de atividades náuticas em represas, resultantes da construção de barragens, que propiciaram a criação de novas áreas para recreação e turismo.

O turismo ecológico, de aventura e outras formas criativas atraem aqueles que procuram a natureza para desfrutar de seus recursos no tempo livre.

Modalidades dirigidas para uma demanda especifica têm sua procura apoiada em recursos naturais primários e pouco explorados; o ecológico e a aventura, que parecem à primeira vista confundir-se com o simples e rústico, nem sempre significam turismo a baixo custo, muito embora não ofereçam alojamentos e serviços sofisticados ou, mesmo, de conforto médio. Na esteira do ambientalismo, estas modalidades buscam áreas "redescobertas" ou "reavaliadas" no atual contexto da ecologia. A atração predominante são os elementos paisagísticos, isolados ou em conjunto, porém, e principalmente, diferenciados do usual.
Os exemplos se multiplicam (roteiros na Amazônia, no Pantanal, nas cavernas do Alto Vale do Ribeira) e as "descobertas" ainda podem suprir, por muito tempo, a esta demanda. Uma destas "descobertas" recentes são as ruinas, decorrentes da erosão subaérea. existentes em Itararé (São Paulo), que poderão brevemente ganhar status de atração turistica. Da mesma forma, vêm se transformando em atrações certos recursosnaturaissituados em áreas próximas aos centros urbanos que, no passado, eram utilizados para o lazer da população e que, hoje, aparecem incluídos em roteiros ecológicos. Isto mostra mudanças de mentalidade quanto ao uso do tempo livre e, por outro lado, permanência de antigos atrativos que ganharam uma nova conotação.

O termalismo é outra tendência que vem se firmando no Brasil. Particularmente no Estado de São Paulo, o termalismo aparece relacionado à iniciativa particular que explora águas quentes, na maioria das vezes, descobertas nas diversas tentativas feitas em busca de petróleo. Assim, não apenas as tradicionais estâncias hidrominerais se renovam com essa procura, como também as novas áreas vêm se integrando ao termalismo favorecidas pelos fluxos que têm sua origem no desenvolvimento regional.

Estas novas formas de ocupação do espaço apresentam, entretanto, algumas diferenças em relação às antigas estâncias hidrominerais, conforme mostra a análise feita em 9 balneários e 17 termas que aponta características principais do aproveitamento das estâncias paulistas revelando aspectos dos investidores, das operadoras e do perfil da demanda (KUSUMOTO, 1992).

Assim, as estâncias tradicionais exploravam suas águas minerais por meio dosbalneários (públicos ou particulares) que, raramente, apresentavam vínculos com a estrutura de alojamento, e estavam direcionados para equipamentos de saúde.

Hoje, ao contrário, a exploração de fontes termais aparece normalmente associada à presença de águas quentes, equipamentos de lazer e alojamentos. Três tendências principais podem ser observadas: a criação de grandes complexos de lazer, a venda de títulos de clubes e a venda de lotes para a construção de segundas-residências.

Portanto, enquanto o balneário tradicional das estâncias hidrominerais estava voltado para a saúde, as novas formas de termalismo dos clubes, condomínios e grandes complexos hotelciros aparecem estruturados em função das atividades de lazer. A divulgação feita pelas antigas estâncias hidrominerais privilegiava, e continua privilegiando, a propriedade terapêutica das águas para fins de saúde ou de estética, enquanto as termas atuais propagam as virtudes de suas águas (e de seus serviços) para o lazer.

Uma diferença marcante entre a forma tradicional e a nova é a venda de títulos de propriedade de clubes. Este fato, entretanto, é relativamente recente, porém vem aumentando consideravelmente através de investimen- 
tos da iniciativa privada, como acontece em Presidente Epitácio, Presidente Prudente, Paraguaçu Paulista, Araçatuba, Fernandópolis, Anhangüera, Piratininga, Rio Preto e outras cidades do Estado de São Paulo e, também, do Paraná, como Maringá e Londrina (KUSUMOTO, 1992:38).

A captação do fluxo ocorre em função da distância, da disponibilidade de tempo livre e do custo do deslocamento necessário para alcançar o núcleo receptor. Na capital paulista, algumas operadoras incluem cidades com águas termais e minerais em seus roteiros. Entre estas aparecem, além daquelas mais próximas da capital como Serra Negra, Águas de São Pedro e Águas de Lindóia, outras estâncias mais distantes como Águas de Santa Bárbara, Piratininga, Presidente Epitácio e Araçatuba (KUSUMOTO, 1992:32).

Percebe-se que, enquanto as estâncias mais próximas da capital de São Paulo se beneficiam do fluxo ali gerado, as outras, mais distantes, têm a sua demanda garantida pelos centros urbanos de expressão regional e, até mesmo, pelos Estados vizinhos a São Paulo. Presidente Prudente, Presidente Epitácio e Paraguaçu Paulista, por exemplo, têm recebido fluxos procedentes do Mato Grosso do Sul e do Paraná. É de se desejar que o Oeste Paulista, através deste recurso natural diferencial (águas quentes) associado à oferta de equipamentos e serviços adicionais cative, como já vem acontecendo. fluxos de países vizinhos, como a Argentina e o Uruguai.

$\mathrm{O}$ culto à beleza e à saúde, atualmente entendidos como necessidades na busca pela melhor qualidade de vida, respondem pela proliferação de academias e similares e, também, de SPAs e clubes de saúde que, mais de perto, interessam a este enfoque.

Muito embora tenham renascido no momento atual, os SPAs já eram conhecidos pelos antigos gregos que viajavam no próprio país e pelos países vizinhos para fins de negócios, enriquecimento cultural e saúde, sendo que os SPAs daquela época já estavam equipados para programas de emagrecimento (GUNN, 1988:37).

Assim como acontece com as estâncias hidrominerais os SPAs aproveitam recursos naturais (neste caso os elementos da paisagem) integrados a equipamentos e serviços. Nos países desenvolvidos, muitas vezes os SPAs estão somente em contato com recursos naturais da paisagem, e em outras buscam a combinação destes com o cultural, o recreacional, as facilidades esportivas e um grande desenvolvimento da vida social (BAUD-BOVY \& LAWSON, 1977).

No Brasil, os SPAs e clubes de saúde estão localizados nas proximidades de grandes centros urbanos, em áreas tranqüilas, junto a reservas florestais e cachoeiras utilizando, principalmente, os recursos naturais paisagísticos aliados a equipamentos, facilidades e serviços adicionais. A característica marcante, entretanto, é a oferta de programasde emagrecimento associados a equipamentos, serviços médicos e dietas apropriadas para tal fim A diversidade de exemplos mostra que, hoje, os SPAs e clubes de saúde já constituem fortes componentes de uma demanda específica que utiliza programas especiais para fins de emagrecimento, estética, desintoxicação, nutrição, relaxamento, combate ao stress, prática de atividades fisicas, chekup, turismo, recreação e lazer.

O elenco da oferta já começa a interessar algumas operadoras e agências de turismo que reservam espaços para a propaganda destas opções concentradas no Centro Sul Brasileiro, como a capital paulista e outras cidades desse Estado (Sorocaba, Cabreúva, São Roque, Guarujá, Campos do Jordão, Embu, Itatiba e Atibaia), além de Curitiba (Paraná), Caldas da Imperatriz (Santa Catarina)e Angra dos Reis (Rio de Janeiro); e no Nordeste Brasileiro como Salvador (Bahia), Fortaleza (Ceará), Maceió (Alagoas), Recife (Pernambuco) e Natal (Rio Grande do Norte).

Embora até o momento pouca importância tenha sido dispensada ao estudo sistemático destas modalidades, é incontestável o seu significado para o conhecimento da recreação $e$ do turismo.

\section{CONSIDERAÇÕES FINAIS}

A análise de tendências contemiporâneas no aproveitamento de recursos naturais mostra, em geral, que a recreação e o turismo concorrem para transformar a organização espacial, principalmente quando esta utilização vem acompanhada pela oferta de equipamentos e serviços. Por exemplo, o caráter massivo dos deslocamentos no tempo livre e a preocupação com a segurança têm contribuído para a proliferação de segundas-residências em grandes condomínios fechados. No Estado de São Paulo, esta organização espacial (que já aconteceu na orla litorânea na década passada) atinge, hoje, o interior, favorecida pela venda de lotes e pela construção de grandes complexos hoteleiros em clubes (que cobram taxa de manutenção mensal ou trimestral), localizados nas proximidades de centros urbanos de expressão regional, interligados por vias de acesso em boascondições. Nestas áreas, os recursos naturais aproveitados para o turismo e recreação vêm sendo dotados de equipamentos e serviços que contribuem para a valorização do empreendimento e para a organização e transformação do espaço

Muitas vezes, entretanto, a transformação do espaço poderá gerar efeitos negativos como ocorre, por exemplo, com o termalismo em algumas áreas. Isto porque os grandes complexos dotados de facilidades acabam por confinar a clientela num espaço delimitado, transformando o empreendimento num verdadeiro enclave, alheio à comunidade local. 
As tendências contemporâneas, privilegiando os recursos naturais, assumem especial significado, pois constituem novas forças criando novos espaços turísticos, novas maneiras de conceber a utilização dos espaços já existentes ou de revitalizar áreas decadentes. $\mathrm{O}$ impulso gerado por estas tendências concorre para estimular as mais diversas atividades, para ativar a indústria de materiais e equipamentos compativeis com as novas modalidades, e para criar espaços diferenciados. Paradoxalmente, entretanto, a exploração excessiva dos recursos naturais irá colocá-los, enquanto atrações, num plano secundário, pois a proliferação de atividades resultará na diversificação e no aprimoramento de equipamentos e serviços que poderão ofuscar a sua atratividade intrínseca.

Resta considerar que a coincidência de recursos naturais numa mesma área oferece possibilidades que, acrescidas de características culturais e sociais, concorrem para definir as regiões turísticas. Finalmente, nunca é demais lembrar que a análise de tendências pode indicar os novos caminhos para a compreensão do futuro desenvolvimento turístico, sendo imprescindivel para fundamentar o planejamento.

\section{REFERÊNCIAS BIBLIOGRÁFICAS}

BAUD-BOVY, Manuel \& LAWSON, Fred. 1977. Tourism and recreation development. Boston: CBI, 209p.

CAZES, George, LANQUAR, Robert \& RAYNOUARD, Yves. 1980. L'aménagement touristique. Paris: PUF. (Coleção Que Sais-je?)

FORNEAU, F. 1983. Loisirs de proximité et résidences secondaires autour d'une métropole régionale: le cas de Séville. Paris: Norois, p. 120/619-24.

GUERRA, Antonio Teixeira. 1969. Recursos naturais do Brasil (Conservacionismo). Rio de Janeiro: IBGE.

GUNN, Claire A. 1988. Vacationscape. Designing tourist regions USA. A. Von Nostrand: Reinhold Book.

KUSUMOTO, Marcia Hitomi. 1992. As águas no Estado de São Paulo. Fonte natural de turismo e de lazer. São Paulo: ECA-USP, 58p. (Trabalho de Conclusão de Curso)

LAGE, Beatriz Helena Gelas. 1992. Segmentação do mercado turístico. Turismo em Análise. São Paulo, v.3, n.2, nov. p.61/74.

PEARCE, Douglas. 1988. Tourism today. A geographical analysis. London: Longman, 227p.

PENTEADO, Antonio Rocha. 1992. Turismo e meio ambiente: uma sintese geográfica. Turismo em Análise. São Paulo, v.3, n.1, maio, p. 12-20.

SMITH, Stephen. 1992. Geografia recreativa. Investigación de potenciales turisticos. México: Trillas, 289p.

VIZCARRA, Miguel Ángel Ramirez. 1990. Turismo náutico internacional. México: Trillas, $165 \mathrm{p}$. 